\title{
Risks of beryllium disease related to work processes at a metal, alloy, and oxide production plant
}

\author{
Kathleen Kreiss, Margaret M Mroz, Boguang Zhen, Herbert Wiedemann, Barbara Barna
}

\begin{abstract}
Objectives-To describe relative hazards in sectors of the beryllium industry, risk factors of beryllium disease and sensitisation related to work process were sought in a beryllium manufacturing plant producing pure metal, oxide, alloys, and ceramics.

Methods-All 646 active employees were interviewed; beryllium sensitisation was ascertained with the beryllium lymphocyte proliferation blood test on 627 employees; clinical evaluation and bronchoscopy were offered to people with abnormal test results; and industrial hygiene measurements related to work processes taken in 1984-93 were reviewed. Results-59 employees (9.4\%) had abnormal blood tests, 47 of whom underwent bronchoscopy. 24 new cases of beryllium disease were identified, resulting in a beryllium disease prevalence of $4.6 \%$, including five known cases (29/632). Employees who had worked in ceramics had the highest prevalence of beryllium disease $(9.0 \%)$. Employees in the pebble plant (producing beryllium metal) who had been employed after 1983 also had increased risk, with a prevalence of beryllium disease of $6.4 \%$, compared with $1.3 \%$ of other workers hired in the same period, and a prevalence of abnormal blood tests of $19.2 \%$. Logistic regression modelling confirmed these two risk factors for beryllium disease related to work processes and the dependence on time of the risk at the pebble plant. The pebble plant was not associated with the highest gravimetric industrial hygiene measurements available since 1984 .

Conclusion-Further characterisation of exposures in beryllium metal production may be important to understanding how beryllium exposures confer high contemporary risk of beryllium disease.
\end{abstract}

(Occup Environ Med 1997;54:605-612)

Keywords: beryllium; occupational lung disease; lymphocyte proliferation test; surveillance; exposureresponse

Beryllium exposure leads to cell mediated immunological sensitisation in a small percentage of workers exposed to beryllium aerosols, dusts, or fumes; of the sensitised workers, many have granulomatous lung disease. ${ }^{1-3}$ Prevention of beryllium disease depends on knowledge of risk factors which can be modified. Although inborn genetic factors are associated with risk of disease in those exposed to beryllium, ${ }^{4}$ these cannot be changed in an existing workforce exposed to beryllium. In contrast, work related risk factors offer the opportunity to lower risk of beryllium disease and to understand the exposure characteristics associated with high disease rates. In our previous studies of plant workforces exposed to beryllium, we found risks of beryllium sensitisation or disease related to work processes in three plants representing single sectors of the beryllium industry. These include machining of beryllium metal, ${ }^{1}$ grinding, dicing, and drilling of beryllia ceramics, ${ }^{2}$ dry pressing, and research and development in a plant which manufactured beryllia ceramics historically. ${ }^{3}$ We report here the results of epidemiological and exposure surveillance in a plant which encompasses most sectors of the beryllium industry in production of beryllium metal, alloys, and beryllium oxide from which ceramics were made historically. We sought to describe risks of beryllium disease related to work processes which could provide opportunities for future study of exposure variables conferring excess risk. Understanding of qualitative and quantitative exposure-response relations is critical to prevention of disease in the many sectors of the beryllium industry.

The plant opened in 1953 to produce beryllium-copper alloy, which is cast and fabricated into tubes, wire, sheet, plates, and metal parts before shipment to other factories to become finished products. Beryllium metal operations were developed in about 1957 in buildings and under management which were largely separate from alloy operations. Beryllium metal is produced from beryllium hydroxide through a chemical process. The two component areas involved in beryllium metal production are the pebble plant, which contains fluoride and reduction furnaces, and vacuum melting. ${ }^{5}$ As the crystalline structure of cast beryllium metal is unsuitable for many applications, the metal is partitioned into differing grades of powder and pressed into metal shapes. A machine shop grinds and finishes many of the cast and pressed beryllium and alloy parts.

The plant also reclaims scrap beryllium and alloy metal and began production of Albemet, a beryllium-aluminum alloy, in 1990 . Histori- 


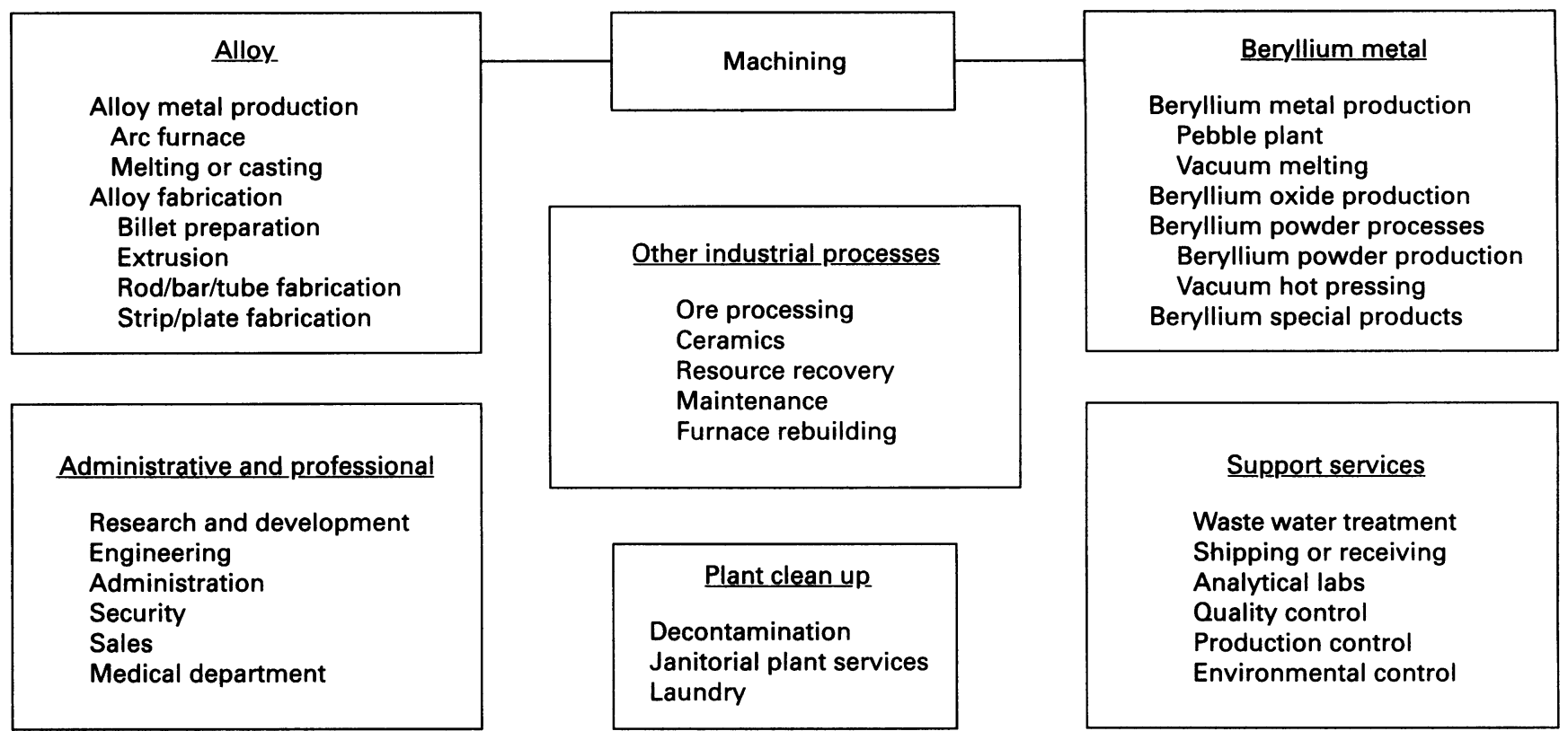

Figure 1 Process classifications and their subgroups used in work history analyses for risks related to work processes and cumulative exposure estimates.

cally, the plant produced beryllium hydroxide from ore until 1972. Beryllium oxide for ceramics has been produced since about 1958 at the metal side of the plant. Beryllia ceramic products were produced at the plant until the operation was moved to another factory between 1980 and 1984. Production of beryllium pebbles in metal production increased coincidentally during a similar period, doubling in 1979, declining to baseline, and then doubling again in 1983-4.

\section{Methods}

POPULATION

We invited all 655 employees on the plant roster during the screening period to participate in screening for beryllium disease after presenting information sessions to each workshift. Five employees had already had a diagnosis of chronic beryllium disease. The management at the plant required all current employees to be interviewed during work time over a 13 month period. The screening blood test for beryllium sensitisation was voluntary.

\section{QUESTIONNAIRE}

The personnel department provided employees with their work histories for review before confidential interviews with non-plant personnel. Trained interviewers administered an abbreviated standardised respiratory questionnaire, ${ }^{6}$ supplemented with additional medical and work history questions (before blood test results were available) usually within two months of drawing blood. For data analysis of work history, jobs were classified by the individual and grouped processes (fig 1).

BLOOD LYMPHOCYTE PROLIFERATION TEST After written informed consent, employees gave a $40 \mathrm{ml}$ blood sample collected in heparinised vacutainer tubes, half of which was sent by overnight courier to one laboratory and half to another laboratory for the beryllium lymphocyte proliferation (BeLP) test. ${ }^{7}$ Split blood samples were collected weekly over a 15 month period from late February 1993 to June 1994. Repeat testing of abnormal and indeterminate results extended blood collection to October 1995.

\section{CLINICAL EVALUATION}

Participants with confirmed abnormal BeLP results or with one abnormal result and an indeterminate result during the study were offered clinical evaluation after additional informed consent, including bronchoscopy for bronchoalveolar lavage BeLP test and transbronchial lung biopsy. People with an initial abnormal blood test that was not confirmed on two subsequent split tests were not referred for clinical evaluation but were offered repeat blood tests after the study. We defined beryllium sensitisation as a repeatable abnormal BeLP test. We defined beryllium disease as granulomas on lung biopsy in the presence of beryllium sensitisation or an abnormal bronchoalveolar lavage BeLP test. ${ }^{8}$

HISTORICAL INDUSTRIAL HYGIENE DATA

We reviewed all computerised industrial hygiene measurements of beryllium mass concentration $(n=124600)$ collected from 1980 to 1993 without regard to particle size or respirable fraction. We excluded 10080 special samples without location codes and 8322 samples that could not be classified as general area, full shift, breathing zone, or lapel samples, most of which were taken between 1980 and 1984 . General area samples $(n=30$ 872) were collected with high volume samplers for 30 minutes in the work area of specific processes. Continuous samples ( $n=59360)$ were also collected, usually over a full workshift or occasionally over 24 hours. Process breathing zone samples were collected for 1-15 minutes with high volume samplers $(n=15787)$. Beginning in 1990, personal lapel samples $(n=179)$ were collected with a monitoring pump positioned on the worker's lapel for the entire work shift for 20 different jobs. 
We estimated daily weighted average (DWA) exposures for a working day with formulas incorporating quarterly average general area, continuous area, and breathing zone measurements based on time studies for most jobs. The DWA formulas were added or changed over the years as jobs changed and were available only since 1984 for most production jobs. In alloy areas, only jobs at the arc furnace, the melting-casting furnaces, and some stripplate operations had DWA formulas. In beryllium metal areas, almost all jobs had DWA formulas. The DWA formulas were not available for jobs in quality control, engineering, decontamination, janitorial, production control, environmental control, administration, security, waste water treatment, and the medical department. We recreated quarterly DWA estimates for individual jobs and job categories with the available formulas and industrial hygiene measurements. If no quarterly measurements existed for a procedure code of a DWA formula, we used measurements from the nearest available quarter to complete the estimate. We created DWAs with existing general area and continuous area sample measurements for workers in alloy rod-bar-tube areas, engineering administration, offices, sales, and waste water treatment. We could not create DWAs for quality control, decontamination, plant cleaning services, production control, environmental control, and security job titles. As these jobs involved tasks in all parts of the plant and in the administrative areas, we assumed that exposure was the average of DWAs for all other jobs during the quarter. We estimated cumulative beryllium exposure for study participants who started employment after 1983 by summing the quarterly DWAs for their job titles, weighted by days of employment in the job title during the quarter, accounting for reported time away from work. The proportion of person-days for which we had job specific DWAs was $90.5 \%$, with the remaining $9.5 \%$ being the all plant average DWA estimates. We calculated average beryllium exposure by dividing cumulative exposure, expressed in $\mu \mathrm{g} / \mathrm{m}^{3}$-days, by the total number of days worked.

The beryllium detection limit for all industrial hygiene samples was $0.1 \mu \mathrm{g} / \mathrm{m}^{3}$, but the industrial hygiene database did not distinguish between samples below or at the detection limit. For the purpose of DWA analyses, we recoded all 0.1 measurements as $0.05 \mu \mathrm{g} / \mathrm{m}^{3}$.

\section{CUMULATIVE INCIDENCE}

The plant medical department supplied names and dates of hire of 24 former employees diagnosed with chronic beryllium disease before the cross sectional screening. The plant management provided us with a count of unique employees by year of hire, with which we calculated a minimum cumulative incidence.

STATISTICAL ANALYSIS

The five current employees carrying a diagnosis of chronic beryllium disease were included as cases in most analyses. We excluded them from the analyses of chest and dermatological symptoms and workplace risk factors as they answered these questions after knowing their diagnosis. The prevalent cases were included in work history analysis until their date of diagnosis.

We analysed questionnaire and laboratory results with PC SAS, ${ }^{9}$ using $\chi^{2}$, Fisher's exact test, Student's $t$ test, and Wilcoxon's rank sum test, as appropriate. We chose a probability of 0.05 for significance. For logistic regression (PROC LOGISTIC in PC SAS), we used variables from the univariate analyses that were associated with beryllium disease or abnormal BeLP test with a statistical significance of $<0.25$ and tested the assumption that the logit was linear in the continuous variables. We used stepwise selection with a $P$ value criterion of $<0.05$ to determine which variables and possible interaction terms should be included in the final model.

Data on industrial hygiene were left censored due to the detection limit of $0.1 \mu \mathrm{g} / \mathrm{m}^{3}$ and did not fit a normal or a log normal distribution. We used medians, ranges, and quartiles to describe these data. We compared groups with Wilcoxon's rank sum test, $\chi^{2}$ test, and Fisher's exact tests. We compared the mean of the personal lapel samples for each job title within a quarter to the corresponding quarterly DWA estimates with Wilcoxon's sign rank test and Spearman's correlation coefficient.

\section{Results}

DEMOGRAPHIC DATA

Of the 655 employees invited to participate, $646(98.6 \%)$ completed the interview, the rest having left employment, retired, or died before interview. Most employees were male (85.1\%) and non-hispanic white $(94.7 \%)$. The mean age was 43.9 years, with a range of 24 to 61 . Average employment at the plant was 17.6 years, with a range from seven months to 38.3 years. Employees changed work processes an average of 9.4 times throughout their employment (range 1-50), but were employed on an average of only 4.4 different processes (range 1-15).

\section{BLOOD BERYLLIUM BELP TEST RESULTS AND} CLINICAL CLASSIFICATION

Excluding the five employees with a diagnosis of beryllium disease, 627 (97.8\% of those interviewed) had blood drawn for the BeLP test. Fifty people had a confirmed abnormal blood test from either one or two laboratories or had a combination of an abnormal blood test and indeterminate test (table 1). Forty seven of the 50 underwent clinical evaluation. Twenty had granulomas on biopsy in the presence of beryllium sensitisation, and four others had abnormal bronchoalveolar lavage BeLP tests and no granulomas. Of these four people, one had a $29 \%$ lavage lymphocytosis with multinucleated giant cells and no history of cobalt exposure; one had $31 \%$ lymphocytes and fibrosis on biopsy; and the other two had $19 \%$ and $46 \%$ lavage lymphocytes. Three of the four had rebiopsy without obvious granulomas about one year after initial bronchoscopy, and the fourth had a granuloma on rebiopsy. 
Table 1 Clinical evaluation results of employees with abnormal blood test results

\begin{tabular}{|c|c|c|c|c|}
\hline Screening category & $n$ & $\begin{array}{l}\text { Clinically } \\
\text { evaluated } \\
n\end{array}$ & $\begin{array}{l}\text { Beryllium } \\
\text { disease } \\
n\end{array}$ & $\begin{array}{l}\text { Sensitised to beryllium } \\
\text { but without disease } \\
n\end{array}$ \\
\hline \multicolumn{5}{|l|}{ Confirmed abnormal in both } \\
\hline \multicolumn{5}{|l|}{ Confirmed abnormal in one } \\
\hline laboratory & 16 & 16 & 10 & 6 \\
\hline \multicolumn{5}{|l|}{ Initially abnormal with indeterminate } \\
\hline retest & 19 & 17 & 5 & 3 \\
\hline Intially abnormal with normal retests & 9 & 0 & - & $4 \dagger$ \\
\hline Total & 59 & 47 & 24 & $19^{\circ}$ \\
\hline
\end{tabular}

* One of those classified as sensitised to beryllium but without disease did not undergo clinical evaluation.

† Six of nine employees were retested in the autumn of 1995, allowing four to meet the definition of a case of sensitisation; disease has not been excluded.

The remaining 23 people did not have beryllium disease documented by biopsy or lavage BeLP test abnormalities; however, three had increased lavage lymphocyte proportions of $22 \%, 27 \%$, and $37 \%$.

Nine people had initial abnormal blood tests, retested normal on two subsequent tests, and were not offered clinical evaluation. Six of the nine had follow up blood testing in the autumn of 1995, four of whom had abnormal BeLP test results confirming beryllium sensitisation.

PREVALENCE OF BERYLLIUM DISEASE, SENSITISATION, AND ABNORMAL BLOOD TEST The prevalence of abnormal blood BeLP tests was $9.4 \%$ (59/627), excluding previously diagnosed cases of beryllium disease as they did not have blood tests as part of this study. The prevalence of beryllium sensitisation was $6.9 \%$ (43/627), again excluding the known cases of disease. The prevalence of beryllium disease, including previously diagnosed cases in the current workforce, was $4.6 \%$ (29/632). Twelve people with abnormal blood tests did not have clinical evaluation required for classification as beryllium disease.

ASSOCIATIONS BETWEEN DEMOGRAPHIC DATA AND CHRONIC BERYLLIUM DISEASE

We compared the 24 new cases of beryllium disease and the five previously diagnosed cases with all employees with normal blood test results. The 29 cases with beryllium disease were significantly younger than others at age of diagnosis (39.2 $v 44.0$ years, $\mathrm{P}=0.005$ ). They did not differ significantly from the remainder of study participants in sex, race, ethnicity, cigarette smoking, pack years of smoking, or time since first employment. Cases of beryllium disease had time since first employment ranging from 1.8 to 27.5 years. No significant differences existed in chest or dermatological (rash, ulcer, or delayed healing of cuts) symptoms between new cases of beryllium disease and those with normal blood tests. Of the five previously diagnosed cases of disease, one reported a usual cough and phlegm, four reported wheezing occasionally apart from colds, and two reported having to walk more slowly than people of their age on the level because of breathlessness. Patients with beryllium disease were no more likely than normal people to report having been in an accident or unusual incident that may have resulted in high beryllium exposures $(58.3 \% v 53.9 \%$, $\mathrm{P}=0.67$ ).

ASSOCIATIONS BETWEEN WORK PROCESS AND CASES OF BERYLLIUM DISEASE

We assessed possible beryllium exposureresponse relations by comparing prevalences of work processes in cases and normal people and by comparing disease prevalence by working groups. The 29 disease cases were more likely than those with normal blood tests to have worked in ceramic fabrication $(48.3 \% v$ $24.1 \%, P=0.004)$. In assessing prevalence of disease among employees in different work processes, we controlled for overestimates of risk by removing employees who worked in ceramics from the prevalence estimates for other processes (table 2). When we looked at grouped processes, we found that cases worked in beryllium metal production (pebble plant and vacuum melting) more than normal people $(51.7 \% v 34.2 \%, \mathrm{P}=0.05)$. Two cases of beryllium disease had worked only for purchasing or accounting. Another had worked only in alloy maintenance.

As many employees without ceramic exposure had started working after ceramics production stopped in the plant, we examined whether the increased risk of beryllium disease among ceramic employees was attributable to secular trends in exposures or latency. When we restricted the analysis to all employees who began working before 1984 (last date of ceramic fabrication work), a significant difference remained in the prevalence of disease, $9.3 \%(14 / 150)$ in ceramics workers compared with a prevalence of $3.9 \%$ among workers never in ceramics $(P=0.025)$. Beryllium metal production was not associated with significantly increased prevalence, even when ceramics workers were removed from the analysis.

Conversely, we looked at all employees who began working after ceramics work was moved from the plant $(n=190)$ and found an $8 \%$ prevalence $(4 / 50)$ in beryllium metal production compared with a $0.7 \%$ prevalence $(1 / 140)$ among employees in all other processes $(\mathrm{P}=0.02)$. Looking at the two process areas in beryllium metal production, those employees working in the pebble plant had a $7.3 \%$ prevalence (3/41) compared with a $1.3 \%$ prevalence $(2 / 148)$ among other employees $(P=0.07)$, and employees working in vacuum melting had a $13.3 \%$ prevalence $(2 / 15)$ compared with $1.7 \%$ (3/175) among people in all other processes $(P=0.05)$. Six employees had worked in both the pebble plant and vacuum melting, of whom one had disease. The prevalences of beryllium disease among all pebble plant workers and vacuum melting workers hired after 1983 were $6.4 \%$ and $12.5 \%$, respectively.

Logistic regression analysis reflected the univariate analyses. We included 12 demographic and workplace variables in the creation of our model: sex, race, smoking status, pack years of smoking, time since first employment, work in another beryllium facility, work around beryllium fluoride, pebble plant, vacuum melting, alloy extrusion, ceramics, and shipping or 
Table 2 Adjusted prevalences of beryllium disease and abnormal blood BeLP test by work process

\begin{tabular}{|c|c|c|c|}
\hline Process & At risk (n) & Beryllium disease & Abnormal blood test ${ }^{*}$ \\
\hline Ceramics & 155 & 9.0 & 11.6 \\
\hline Beryllium metal production $\dagger$ & 155 & 5.2 & 14.2 \\
\hline Pebble plant $\dagger$ & 134 & 5.2 & 13.4 \\
\hline Vacuum melting $\ddagger$ & 21 & 4.8 & 19.0 \\
\hline Shipping or receiving $\ddagger$ & 17 & 5.9 & 5.9 \\
\hline Furnace rebuild $\ddagger$ & 21 & 0 & 4.8 \\
\hline Office area & 65 & 3.1 & 7.7 \\
\hline Beryllium powder processing $\ddagger$ & 47 & 2.1 & 8.5 \\
\hline Maintenance & 104 & 2.9 & 11.5 \\
\hline \multicolumn{4}{|l|}{ Engineering research and } \\
\hline developmentł & 52 & 1.9 & 7.7 \\
\hline Alloy metal production $\ddagger$ & 69 & 4.3 & 5.8 \\
\hline Alloy melting or casting & 65 & 4.6 & 6.2 \\
\hline Analytical laboratory $\ddagger$ & 25 & 4.0 & 20.0 \\
\hline Alloy arc furnace $\ddagger$ & 18 & 0 & 0 \\
\hline
\end{tabular}

* Prevalences are based on all employees at risk and do not match prevalence comparisons in the text, which were made with employees with normal blood tests.

† All employees who ever worked in ceramics which have been removed from these groups.

$¥$ All employees who have ever worked in ceramics or the pebble plant have been removed from these groups.

Table 3 Logistic regression model of variables predictive of beryllium disease

\begin{tabular}{|c|c|c|c|}
\hline Independent variables & $\begin{array}{l}\text { Estimated } \\
\text { coefficients }\end{array}$ & $O R(95 \% C I s)$ & Pvalue \\
\hline \multicolumn{4}{|l|}{ Beryllium disease model: ${ }^{\star}$} \\
\hline Intercept & -3.7172 & - & 0.0001 \\
\hline Ceramics history & 1.4790 & $4.39(1.83$ to 10.50$)$ & 0.0009 \\
\hline Pebble plant & 3.1561 & 23.48 (4.39 to 125.52$)$ & 0.0002 \\
\hline Years since first employment & -0.0016 & $1.00(0.99$ to 1.05$)$ & 0.9569 \\
\hline Pebble plant $x$ years since first employment & -0.1764 & $0.84(0.75$ to 0.94$)$ & 0.0025 \\
\hline
\end{tabular}

* This model cannot be used to accurately measure risk for pebble plant employment as time since first employment is a continuous variable and cannot be interpreted at the high and low end of the continuum. This is an unavoidable problem when a continuous covariate is modelled linearly in the logit. This does not affect the risk estimate for ceramics.

receiving. We did not include beryllium metal production (the grouped process of pebble plant and vacuum melting) to find which of the two processes was contributing to the increased risk. We also included possible interaction terms. Four variables were included in the final model (table 3): ceramics, work in the pebble plant, time since first employment, and an interaction term between time since first employment and the pebble plant. The odds ratio (OR) of beryllium disease for people working in ceramics was 4.4. Work in the pebble plant interacted with time since first exposure and reflects the previous analysis in which beryllium metal production was a risk factor since 1984. The model predicts that pebble plant work conferred no additional risk for a person with employment of 17.6 years but a 5.7-fold risk for someone first employed in 1985.

ASSOCIATIONS BETWEEN DEMOGRAPHIC DATA, WORK PROCESSES, AND ABNORMAL BLOOD TESTS We compared the 35 employees with abnormal blood tests but without documented beryllium disease with those employees with normal blood tests. People with abnormal blood tests were no different in age, sex, race, smoking status, pack-years of smoking, or time since first employment. There were also no significant differences in chest or skin symptoms, although those with abnormal blood tests (but without disease) were more likely than those with normal blood tests to report having their job changed due to a rash $(36.0 \% \quad v 13.6 \%$, $\mathrm{P}=0.007$ ), and were more likely to have had a rash within the month before interview $(28 \% v$
$8.8 \%, \mathrm{P}=0.008)$. No difference existed between the two groups in reports of having been exposed to beryllium in an accident or unusual incident.

People with abnormal blood tests were more likely than people with normal blood tests to work in the analytical laboratory $(17.1 \% v$ $5.5 \%, \mathrm{P}=0.02$ ). Restricting the analysis to people employed before 1984, the association with the analytical laboratory remained $(22.7 \% v$ $6.5 \%, \mathrm{P}=0.02)$. For people employed after 1983, employees with abnormal blood tests only were more likely to have worked in the pebble plant $(46.2 \%$ v $20.5 \%$ among others, $\mathrm{P}=0.04$ ); the prevalence of abnormal blood tests among pebble plant workers, including cases of beryllium disease, was $19.2 \% v 5.8 \%$ among others.

We included 16 variables and possible interaction terms in the creation of our logistic regression model for abnormal blood BeLP test (but without beryllium disease) and only work in the analytical laboratory entered the model with an OR of 3.6.

\section{HISTORICAL ENVIRONMENTAL MEASUREMENTS} (1984-93)

Full shift and continuous area samples $(n=59$ 360 ) had a median ( $\max$ ) beryllium concentration of $0.6(1290) \mu \mathrm{g} / \mathrm{m}^{3}$. The 30872 general area samples had a median ( $\max$ ) of 0.4 (2615) $\mu \mathrm{g} / \mathrm{m}^{3}$. The 15787 breathing zone samples had a median $(\max )$ of $1.4(3750) \mu \mathrm{g} / \mathrm{m}^{3}$; and exceeded $5 \mu \mathrm{g} / \mathrm{m}^{3}$ in $18.5 \%$ of samples and the peak exposure limit of $25 \mu \mathrm{g} / \mathrm{m}^{3}$ in $3.6 \%$ of samples. The 179 personal lapel samples had a median (range) of $1.0(0.1-52.6) \mu \mathrm{g} / \mathrm{m}^{3}$.

Median general area measurements in different work areas ranged from 0.1 to $0.7 \mu \mathrm{g} / \mathrm{m}^{3}$ with alloy arc furnace and alloy melting-casting areas having the highest median value and the arc furnace having the highest percentage $(15.0 \%)$ of measurements over the $2 \mu \mathrm{g} / \mathrm{m}^{3}$ standard. Median breathing zone samples ranged from 0.1 to $2.0 \mu \mathrm{g} / \mathrm{m}^{3}$, with beryllium powder and laundry areas having the highest median values and furnace rebuild having the highest percentage $(28.6 \%)$ of measurements over the short term exposure limit of $5 \mu \mathrm{g} / \mathrm{m}^{3}$.

Quarterly DWA estimates were available for 18 process areas (based on our groupings in fig 1) for 40 quarters in 1984-93. Some process areas had multiple jobs with DWA estimates. Quarterly job specific DWAs ranged from 0.05 to $63.11 \mu \mathrm{g} / \mathrm{m}^{3}$, with alloy arc furnace workers and furnace rebuild workers having the highest median DWA estimates at $1.65 \mu \mathrm{g} / \mathrm{m}^{3}$ and 1.63 $\mu \mathrm{g} / \mathrm{m}^{3}$, respectively. These two job descriptions also had the highest percentages of DWA estimates over the $2 \mu \mathrm{g} / \mathrm{m}^{3}$ standard, $38 \%$ and $40 \%$ respectively.

Jobs characterised with personal lapel samples had one to seven measurements per quarter in 1990-92, with beryllium oxide production, alloy melting and casting, and the arc furnace having the highest median lapel sample measurements $\left(3.80,1.75\right.$, and $1.75 \mu \mathrm{g} / \mathrm{m}^{3}$, respectively) and the highest percentages of samples over the $2.0 \mu \mathrm{g} / \mathrm{m}^{3}$ standard $(64.3 \%$, $47.2 \%$, and $44.4 \%$, respectively). Analysis of 
Table 4 Pebble plant exposures from 1984 to 1993

\begin{tabular}{lllll}
\hline Exposure assessment method & $n$ & $\begin{array}{l}\text { Median } \\
\left(\mu g / m^{3}\right)\end{array}$ & $\begin{array}{l}>2 \mu g / m^{3} \text { or pertinent } \\
\text { standard }\end{array}$ & Range $\left(\mu g / m^{3}\right)$ \\
\hline General area measurement & 13296 & 0.4 & 6.4 & $0.1-79.2$ \\
Breathing zone measurement & 1456 & 1.1 & 11.0 & $0.1-293.3$ \\
Daily weighted average & 223 & 0.7 & 4.0 & $0.1-7.9$ \\
Lapel sample (1990-2) & 40 & 0.9 & 27.5 & $0.2-19.0$ \\
\hline
\end{tabular}

^ Beryllium standard for short term exposure limit for breathing zone measurements is $5 \mu \mathrm{g} / \mathrm{m}^{3}$

average personal lapel samples and corresponding quarterly DWA estimates for 103 pairs of samples showed that lapel samples tended to be significantly higher than the DWA estimates with a median (range) difference of $-0.19(-27.2$ to 47.8$) \mu \mathrm{g} / \mathrm{m}^{3}(\mathrm{P}=0.06$, Wilcoxan's sign rank test). The paired data had a correlation coefficient of 0.26 .

Estimates of individual cumulative beryllium exposure based on quarterly job specific DWAs were available for 201 people beginning employment after 1983 and before 1994. Individual median (range) cumulative exposures was $1528.1(1.5-5971.9) \mu \mathrm{g} / \mathrm{m}^{3}$-days for the workforce after 1983. The median (range) average beryllium exposure of the workforce was $1.0(0.01$ to 2.66$) \mu \mathrm{g} / \mathrm{m}^{3}$.

\section{EXPOSURES ASSOCIATED WITH HIGH RISK WORK} PROCESSES

As those employed in the pebble plant after 1983 had excess beryllium disease and abnormal blood BeLP tests, we examined exposure measurements and estimates for pebble plant processes (table 4). Samples were coded as to whether or not a respirator was used while performing the work task. Of all breathing zone samples in the pebble plant, $54.4 \%$ were coded as respirator samples compared with $57.0 \%$ of samples in all other areas combined. Of lapel samples in the pebble plant, $43.2 \%$ were coded as respirator samples compared with $39.4 \%$ of lapel samples in other areas.

\section{ASSOCIATIONS BETWEEN EXPOSURE, BERYLLIUM} DISEASE, AND ABNORMAL BLOOD BELP TESTS Cases of beryllium disease among employees employed since $1984(n=5)$ had a median cumulative beryllium exposure of $1635 \mu \mathrm{g} / \mathrm{m}^{3}$ days and a median average exposure of 1.3 $\mu \mathrm{g} / \mathrm{m}^{3}$. They did not differ significantly in these exposure indices from normal people (median cumulative exposure $1518 \mu \mathrm{g} / \mathrm{m}^{3}$-days, $\mathrm{P}=0.47$ and median average exposure $1.0 \mu \mathrm{g} / \mathrm{m}^{3}$, $P=0.27$ ). No significant difference existed between those with abnormal blood tests without disease $(n=13)$ and normal people for cumulative exposure (median for employees with abnormal blood tests $=2153 \mu \mathrm{g} / \mathrm{m}^{3}$-days, $P=0.32$ ) or average beryllium exposure (median for abnormal blood samples $=1.3 \mu \mathrm{g} / \mathrm{m}^{3}$, $\mathrm{P}=0.22$ ). The percentages of days of work with estimated DWAs (rather than job or location specific DWAs) for cases of beryllium disease, employees with abnormal blood tests, and normal people were $0.5 \%, 3.6 \%$, and $10.5 \%$, respectively.

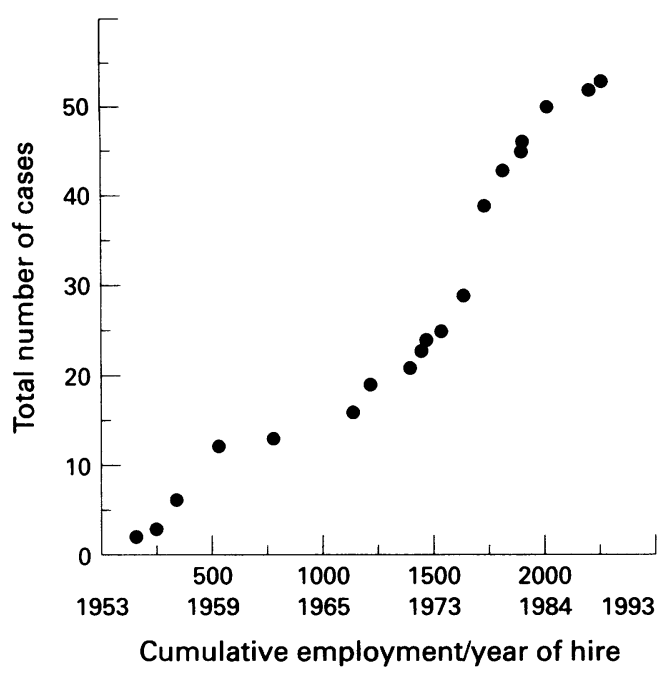

Figure 2 Cumulative number of cases of beryllium disease by cumulative number of people employed at the year of hire.

CUMULATIVE INCIDENCE OF BERYLLIUM DISEASE IN THE PLANT

The minimum cumulative incidence of beryllium disease among the 2274 people ever employed at the plant since it opened in 1953 is $2.3 \%(53 / 2274)$, with little secular variation in rate when cases are plotted by cumulative number of employees at the year of hire (fig 2).

\section{Discussion}

RISK OF BERYLLIUM DISEASE

This cross sectional study of an aging workforce, with historical experience in most segments of the beryllium extraction and production industry, showed the highest prevalences of beryllium sensitisation and disease of any large worker cohort which has been systematically screened. ${ }^{1-3}$ Past ceramic workers in this workforce had high rates of abnormal blood tests (11.6\%) and beryllium disease $(9.0 \%)$ compared with other workers. These prevalences were about double the rates found among ceramics workers in the modern plant to which ceramics work was relocated $(5.9 \%$ for beryllium sensitisation and $4.4 \%$ for beryllium disease) and resembled the rates found among the machinist subgroup of ceramics workers at highest risk in that new plant $(14.3 \%$ beryllium sensitised and $10.2 \%$ with beryllium disease). ${ }^{2}$ Among employees who started working after ceramics operations had been moved out of the plant, pebble plant workers in beryllium metal production had high prevalences of abnormal BeLP tests $(19.2 \%)$, beryllium sensitisation $(14.9 \%)$, and beryllium disease (6.4\%) compared with others. The high rates of abnormal blood tests only and sensitisation only in this group with 10 years maximum employment may reflect an incomplete latency period for beryllium disease arising after sensitisation. The possibility remains that the risk of disease among people sensitised to beryllium differs by work process.

Despite our findings of excess risk of beryllium disease for ceramics and pebble plant workers, employees in non-production jobs had some risk of beryllium sensitisation and disease, as in other cohorts. ${ }^{1-3}$ Employees who had worked only in alloy operations also 
had some risk, which is of interest for the many workers exposed to beryllium-copper alloy in user industries. However, alloy operations confer substantially less risk of beryllium disease than beryllium metal production and ceramic operations, despite higher indices of exposure to beryllium in alloy production.

The time dependence of the risk of beryllium disease in the pebble plant is of particular interest in the light of a major United States Department of Energy research and development effort in the early 1980 s to optimise beryllium production at this plant. Pebble plant processes, which were formerly out of control from an environmental point of view, including the fluoride furnaces, reduction furnaces, and melts crusher, were thought to have been brought under control in the first half of the 1980 s. $^{5}$ These efforts coincided with a transient doubling of 1979 pebble production in 1980 , repeated in 1983-4. Despite considerable improvements motivated to achieve better environmental control, the risk of beryllium disease in the pebble plant increased among beryllium metal production workers hired after 1983, a finding which has also been found for workers hired after 1979 (data not shown). This epidemiological finding suggests that indices used to evaluate exposure of workers have been misleading with respect to the risk to workers of beryllium disease.

\section{EXPOSURE-RESPONSE OBSERVATIONS}

Industrial hygiene measurements, available for the period in which the pebble plant conferred excess risk, did not document higher indices of exposure than lower risk processes. This finding contrasts with the only other surveillance study with usable historical measurements, in which the high risk process of ceramic machining was associated with higher industrial hygiene measurements and DWA estimates than were low risk processes. ${ }^{2}$ In the modern ceramics plant, indices of exposure in machining were similar to the same indices for the modern pebble plant, as were the rates of sensitisation (14.3 $v 14.9)$ and disease (10.2v 6.4).

Risks of beryllium disease or sensitisation related to work processes either reflect exposure factors which confer biological risk or occur by chance alone. The degree of excess risk of beryllium disease conferred by ceramics and the pebble plant are unlikely to have occurred by chance alone. For ceramics workers in this plant, the prevalence of disease is credible, as their rates of disease and sensitisation were similar to the prevalences of the high risk subgroup in the plant to which ceramics operations moved. For pebble plant workers, the period of excess risk of having an abnormal blood test alone coincided with the period with excess risk of disease, making chance a less plausible explanation for the two outcomes in the pebble plant.

The historical measurements may misclassify biologically pertinent exposure in at least three ways. Firstly, DWAs seem to be a poor estimate of personal exposure, as lapel samples correlated weakly with corresponding quarterly
DWA estimates, and lapel samples tended to be higher than the DWA estimates. Secondly, particle size or other characteristic may be more important contributors to risk than is gravimetric measurement without regard to respirability. Thirdly, the methods of beryllium exposure assessment may poorly reflect actual exposures from accidents, which historically often required evacuations in the pebble plant. We found no evidence that respirator use was associated with jobs in the pebble plant, eliminating personal protective equipment as a confounder of exposure characterisation.

The dissociation of high disease risk in the pebble plant from indices of exposure could be interpreted as evidence against an exposureresponse relation. We think that the limits of the historical exposure data make such a conclusion premature. Rather, risk related to a work process which can be currently studied, as in the pebble plant, provides an opportunity to use different methods of exposure assessment which may be more pertinent to biological risk. Comparison of exposure variables in the pebble plant, such as respirable mass, particle number, surface area, and solubility, can be made with low risk processes in this and other plants. Understanding of characteristics of sensitising exposures for beryllium disease may be paradigms for other hypersensitivity diseases, such as occupational asthma.

MISCLASSIFICATION OF SENSITISATION

This surveillance study had the strength of complete interview data on all active employees and nearly complete lymphocyte proliferation data on those employees not known to have beryllium disease. However, the study had several limitations which have resulted in likely misclassification of beryllium disease and sensitisation status. Misclassification of these outcomes of interest may have arisen in laboratory tests and clinical evaluation practices.

The two laboratories conducting BeLP tests on split blood samples produced strikingly inconsistent results, both between laboratories and within laboratories on repeat samples. Our definition of beryllium sensitisation required two abnormal tests separated in time, for comparability with previously published surveillance studies. ${ }^{1-3}$ However, these abnormal test results were often accompanied by normal tests in the same or different laboratory. Of the subset of abnormal cases which could not be confirmed in two split repeat tests in the first 17 months of the study, most of those retested at least 16 months later had a second abnormal test. Cases of beryllium disease occurred in the group with unconfirmed abnormal blood tests, and no difference in rate of beryllium disease existed among those with abnormal tests confirmed in one laboratory compared with those with abnormal tests in both laboratories. Thus, our definition of beryllium sensitisation seems overly restrictive for epidemiological purposes, and we are likely to have missed cases of beryllium disease among those people with abnormal tests not referred for clinical evaluation, many of whom with time met the study criterion for diagnostic evaluation. Certainly, 
the use of two laboratories led to the identification of more cases of beryllium sensitisation and disease than would have occurred with either laboratory alone, a finding that limits the comparison of rates found for this population with some previously published rates. ${ }^{13}$ Use of either laboratory alone (first blood test abnormal and confirmation on subsequent test) would have allowed identification of only $46.5 \%$ of the cases of sensitisation from one laboratory and $48.8 \%$ from the other.

In the face of laboratory insensitivity in finding beryllium sensitisation, we chose to present results for those ever having an abnormal blood BeLP test. Although some employees with one abnormal BeLP test among several may have had false positive results, the theoretical likelihood of a false positive is about $0.06 \%$; this is based on having two stimulation indices (among six in a test) above the mean plus two SDs for the peak stimulation index of unexposed people.

\section{UNDERESTIMATION OF BERYLIIUM DISEASE}

It is likely that this study has underestimated rates of beryllium disease because of three practices in clinical evaluation. Firstly, not all people with abnormal blood tests underwent clinical evaluation, precluding any possibility of making a diagnosis of beryllium disease. Secondly, the lavage BeLP test protocol used by the clinical laboratory for this study used three beryllium concentrations on harvest day 4 , by contrast with three concentrations on harvest days 3 and 5 used in other published studies. ${ }^{1-3}$ As well as this change in protocol, less than three concentrations of beryllium were used in most tests, which is likely to have resulted in lowered sensitivity for detecting an abnormal lavage BeLP test.

Thirdly, the biopsy practices in the clinical evaluations may have resulted in underestimation of disease. The average number of biopsies taken in those undergoing bronchoscopy was four, which is considerably lower than the customary 8-12 biopsies taken in previously published work. ${ }^{1-3}$ In sarcoidosis, the rate of granulomatous abnormalities increases with increasing number of biopsies, ${ }^{10}$ and this seemed to be the case in those undergoing bronchoscopy in this study (data not shown). Although we have documented that granulomas can precede abnormal lavage BeLP tests, the authors from the National Jewish Centre have invariably found granulomas in those with abnormal lavage BeLP tests, although a second bronchoscopy has occasionally been necessary. Rebiopsy of three cases with abnormal lavage BeLP tests but no granulomas in this study did not document granulomas, although all three cases had other evidence of pathological abnormality - such as lymphocytic alveolitis or fibrosis. Only future follow up will clarify whether we have classified them correctly as having beryllium disease. Their exclusion from analyses did not change the risk factors which we have presented here.

A final limitation of this cross sectional study is a healthy worker effect, which would lead to an underestimation of rates of beryllium disease. New cases of beryllium disease identified in this surveillance effort had not come to clinical attention, and only five previously diagnosed cases were still working in the plant. We know that some cases of sensitisation to beryllium progress to subclinical beryllium disease, ${ }^{12}$ and that some of these progress with the passage of time to be clinical cases. The younger age of cases of beryllium disease compared with people with normal blood tests is best explained by the possibility that clinical cases of beryllium disease from this plant have left employment, and the remaining subclinical cases are unrepresentative of the age distribution of the plant population.

\section{IMPLICATIONS FOR FUTURE SURVEILLANCE}

Efficacy is unknown for interventions after early identification of beryllium sensitisation and disease - such as removal from exposure or early treatment. In this context, the main justification of screening is scientific investigation of risk factors and of natural history. Understanding of risk factors can lead to effective primary prevention. Understanding of natural history of beryllium sensitisation, perhaps in concert with genetic risk factors, ${ }^{4}$ can lead to consideration of intervention trials and appropriate policy for secondary prevention. This surveillance study has laid the groundwork for both efforts in the production sectors of the beryllium industry and many client sectors of the industry. The most important priority for further investigation is exposure-risk relations, which will serve as the basis for primary prevention throughout the beryllium industry and may have paradigmatic importance for other common lung hypersensitivity diseases, as well.

We thank the company's administrative officers for their vision in requesting this surveillance study; the plant and corporate medical personnel for coordinating the interview schedules, blood drawing, clinical referrals, and transfer of clinical and laboratory data; the plant and corporate industrial hygienists for historical environmental data; and members of the Beryllium Industry Scientific Advisory Committee for their thoughtfu comments on our work. This work was supported in part by National Institute for Environmental Health Sciences gran K07 ES00214 and by a beryllium company.

1 Kreiss K, Mroz MM, Zhen B, Martyny JW, Newman LS The epidemiology of beryllium sensitization and disease in nuclear workers. Am Rev Respir Dis 1993;148:985-91.

2 Kreiss K, Mroz MM, Newman LS, Martyny JW, Zhen B. Machining risk of beryllium disease and sensitization with median exposures below $2 \mu \mathrm{g} / \mathrm{m}^{3}$. Am $f$ Ind Med 1996;30:16-25.

3 Kreiss K, Wasserman SL, Mroz MM, Newman IS Beryllium disease screening in the ceramics industry: blood lymphocyte test performance and exposure-disease relations. F Occup Med 1993;35:267-74

4 Richeldi L, Sorrentino R, Saltini C. HLA-DPB1 glutamate 69: a genetic marker of beryllium disease. Science $1993 ; 262: 242-4$

5 National Materials Advisory Board, Commission on Engineering and Technical Systems, National Research Council. Beryllium metal supply options. Washington, DC National Academy Press, NMAB-452, 1989.

6 Ferris BG. Epidemiology standardization project. $A m$ Review Respir Dis 1978;118:1-120.

7 Mroz MM, Kreiss K, Lezotte DC, Campbell PA, Newman LS. Re-examination of the blood lymphocyte transformation test in the diagnosis of chronic beryllium disease. $f$ Allergy Clin Immunol 1991;88:54-60.

8 Newman LS, Kreiss K, King TE, Seay S, Campbell PA Pathologic and immunologic alterations in early stages of beryllium disease: re-examination of disease definition and natural history. Am Rev Respir Dis 1989;139:1479-86.

9 SAS. SAS stat user's guide, release 6.03. Cary, NC: SAS, 1988 .

10 Roethe RA, Fuller PB, Byrd RB, Hafermann DR Transbronchoscopic lung biopsy in sarcoidosis. Chest 1980;77:400-2. 